\title{
Comprehensive screening for PD-L1 expression in thyroid cancer
}

\author{
Soomin Ahn',*, Tae Hyuk Kim 2,*, Sun Wook Kim², Chang Seok Ki³, Hye Won Jang4, \\ Jee Soo Kim ${ }^{5}$, Jung Han Kim ${ }^{5}$, Jun-Ho Choe ${ }^{5}$, Jung Hee Shin ${ }^{6}$, Soo Yeon Hahn', \\ Young Lyun $\mathrm{Oh}^{7}$ and Jae Hoon Chung ${ }^{2}$
}

'Department of Pathology, Ewha Womans University School of Medicine, Seoul, Korea

2Division of Endocrinology and Metabolism, Department of Medicine, Thyroid Center, Samsung Medical

Center, Sungkyunkwan University School of Medicine, Seoul, Korea

${ }^{3}$ Department of Laboratory Medicine and Genetics, Samsung Medical Center, Sungkyunkwan University

School of Medicine, Seoul, Korea

${ }^{4}$ Department of Medical Education, Sungkyunkwan University School of Medicine, Seoul, Korea

${ }^{5}$ Division of Breast and Endocrine Surgery, Department of Surgery, Samsung Medical Center,

Sungkyunkwan University School of Medicine, Seoul, Korea

${ }^{6}$ Department of Radiology and Center for Imaging Science, Samsung Medical Center,

Sungkyunkwan University School of Medicine, Seoul, Korea

${ }^{7}$ Department of Pathology and Translational genomics, Sungkyunkwan University School of Medicine,

Seoul, Korea

(*S Ahn and T H Kim contributed equally to this work)

Correspondence should be addressed to $\mathrm{Y}$ L Oh or J H Chung Email bijou@skku.edu or thyroid@ skku.edu

\begin{abstract}
PD-L1 expression is being considered a potential biomarker for response of anti-PD-1 or anti-PD-L1 agents in various tumors. The reported frequency of PD-L1 positivity varies in thyroid carcinomas, and multiple factors may contribute to the variability in PD-L1 positivity. We evaluated the PD-L1 expression in various thyroid cancers on a large scale. A total of 407 primary thyroid cancers with a median 13.7-year of follow-up were included. We evaluated the frequency of PD-L1 expression using a rabbit monoclonal antibody (clone SP142). In addition, we analyzed the relationships between PD-L1 expression and clinicopathologic factors, including TERT promoter, $B R A F$ status and disease progression. Tumoral PD-L1 was expressed in $6.1 \%$ of papillary thyroid carcinomas, $7.6 \%$ of follicular thyroid carcinomas and $22.2 \%$ of anaplastic thyroid carcinomas. The distribution of PD-L1 positivity was different according to cancer histology types $(P<0.001)$. All PD-L1-positive cases of follicular thyroid carcinoma and anaplastic thyroid carcinoma showed strong intensity. The proportions of positivity in PD-L1 positive anaplastic thyroid carcinomas were more than $80 \%$. PD-L1 in immune cells was positive in $28.5 \%$ of papillary thyroid carcinoma, $9.1 \%$ of follicular thyroid carcinomas and $11.1 \%$ of anaplastic thyroid carcinomas. There was no significant association between clinicopathologic variables, disease progression, oncogenic mutation and PD-L1 expression. PD-L1 was highly expressed in a subset of patients with advanced thyroid cancer, such as follicular and anaplastic thyroid carcinoma. Identification of PD-L1 expression may have direct therapeutic relevance to patients with refractory thyroid cancer.
\end{abstract}




\section{Introduction}

Programmed cell death 1 (PD-1) and the PD-1 ligand (PD-L1) show great promise for the treatment of various tumors, including melanoma and non-small-cell lung cancer (Ohaegbulam etal. 2015). PD-1 (B7-1) is a cell-surface glycoprotein normally expressed by macrophage lineage cells and T cells. The binding of PD-1 to one of its ligands, PD-L1 or PD-L2, can inhibit a cytotoxic T-cell immune response, leading to immune tolerance of cells expressing PD-L1 or PD-L2 (Dong et al. 2002). PD-L1 is constitutively expressed on tumor cells as a result of oncogenic signaling or dynamic IFN $\gamma$ expression in tumor microenvironments (Taube et al. 2012). Based on the premise that anti-PD-1 therapy functions by blocking interactions between PD-1 and PD-L1, PD-L1 expression is being considered a potential biomarker for response of anti-PD-1 or PD-L1 agents (Page et al. 2014). Patients with higher levels of PD-L1 expression by immunohistochemistry have improved response rates during anti-PD-L1 therapy for lung cancer and melanoma (Patel \& Kurzrock 2015). Currently, PD-L1 immunohistochemistry using a rabbit monoclonal antibody (clone 22C3) has been approved by the US Food and Drug Administration as a companion diagnostic test for patient selection of pembrolizumab (PD-1-blocking monoclonal antibody) treatment in metastatic non-small-cell lung cancer (Sul et al. 2016). Recently, another PD-1-blocking monoclonal antibody, atezolizumab, was approved by the US Food and Drug Administration for bladder cancer treatment (Rosenberg et al. 2016), and the US Food and Drug Administration also approved the diagnostic test, Ventana PD-L1 (SP142) immunohistochemistry assay, to detect PD-L1 expression of tumor-infiltrating immune cells.

There have been several studies investigating PD-L1 expression in thyroid cancer (Cunha et al. 2013, Angell et al. 2014, Wu et al. 2015, Bastman et al. 2016, Chowdhury et al. 2016). The frequency of PD-L1 positivity ranges from $23 \%$ to $87.5 \%$ of thyroid carcinoma, which varies according to studies and is higher than other cancer types (Cunha et al. 2013, Angell et al. 2014, Patel \& Kurzrock 2015, Wu et al. 2015, Bastman et al. 2016 Chowdhury et al. 2016). Multiple factors may contribute to the wide range of PD-L1 positivity reported across studies, including different antibodies, assay methods, applied thresholds and interpretation (Phillips et al. 2015). Although only membranous staining of PD-L1 is considered positive and the cut-off values of $1 \%, 5 \%$ or $10 \%$ are frequently used to define the positive rate of PD-L1 staining for patient selection in clinical trials, the optimal cut-off value for PD-L1 staining has not been definitively validated.

Clinically, a previous study reported that PD-L1 expression correlates with a higher risk of recurrence and shortened disease-free survival in thyroid cancer patients (Chowdhury et al. 2016). In addition, the BRAF V600E mutation was once reported to be associated with increased PD-L1 expression in papillary thyroid carcinoma (Angell et al. 2014). Although most papillary thyroid carcinomas have indolent clinical behavior, follicular thyroid carcinomas show occasional metastasis and anaplastic thyroid carcinomas are highly aggressive with a mortality of almost 100\% (Xu \& Ghossein 2016). Accurate detection of PD-L1-positive tumors in aggressive thyroid cancers can be important to identify patients who may potentially benefit from anti-PD-L1 therapy.

Herein, we evaluated PD-L1 expression in various thyroid cancers on a large scale with more than ten years of follow-up. We used a Ventana PD-L1 (SP142) immunohistochemistry assay and interpreted the immunohistochemistry results semiquantitatively. The frequency of PD-L1 expression in various thyroid cancers and the relationship between PD-L1 expression and clinicopathologic factors including $B R A F$, TERT promoter status and disease progression were evaluated.

\section{Materials and methods}

\section{Case selection}

A total of 407 primary thyroid cancers were included (papillary thyroid carcinoma $n=326$, follicular thyroid carcinoma $n=66$, poorly differentiated thyroid carcinoma $n=6$ and anaplastic thyroid carcinoma $n=9$ ). Of six poorly differentiated thyroid carcinomas, one had co-existing papillary thyroid carcinoma and another had co-existing follicular carcinoma. The samples were obtained from patients who underwent surgical resection for primary thyroid cancer at the Samsung Medical Center, Seoul, Korea, between 1994 and 2004. Clinicopathological information, including age, sex, the presence of Hashimoto disease, histologic type, tumor size, multiplicity, margin status, pT, pN stage, disease relapse and survival data, was evaluated by reviewing the medical records. Patients lost during follow-up or who died of causes other than thyroid cancer were not included in the survival analysis. The study was approved by the institutional review board of Samsung Medical Center (IRB File No.: 2015-04-007).

Published by Bioscientifica Ltd. 


\section{PD-L1 immunohistochemistry}

In all cases, we performed PD-L1 immunohistochemistry using tissue microarrays. Tissue microarrays consisted of four $2.0 \mathrm{~mm}$ cores from each tumor. A pathologist (SA) reviewed the slide of thyroidectomy and marked areas for tissue microarray. Four areas including center and periphery of tumor were chosen for tissue microarray. Formalin-fixed, paraffin-embedded tissues were sliced to a $4-\mu \mathrm{m}$ thickness and dried at $60^{\circ} \mathrm{C}$ for $30 \mathrm{~min}$. The anti-PD-L1 immunohistochemistry (anti-human PD-L1 rabbit monoclonal, 1:25, clone SP142, Spring Bioscience, Pleasanton, CA, USA) staining was performed on a BenchMark automated immunostainer (Ventana, Tucson, AZ, USA). Antigen retrieval was performed for $92 \mathrm{~min}$ with CC1 buffer, and the antibody was incubated for $120 \mathrm{~min}$ at $37^{\circ} \mathrm{C}$ using the Ventana BenchMark XT platform. Signal visualization was achieved with the OptiView DAB immunohistochemistry detection kit (Ventana, Catalog number 760-700) and OptiView Amplification kit (Ventana, Catalog number 860-099). Tonsil squamous epithelium was used as a PD-L1 immunohistochemistrypositive control (Fig. 1A) (Phillips et al. 2015).

PD-L1 immunohistochemistry microscopy results were interpreted by two experienced pathologists (SA and YO). PD-L1 expression was evaluated in tumor cells and tumor-infiltrating lymphocytes. For tumor cells, positive PD-L1 staining was defined as complete and/or partial circumferential linear plasma membrane staining at any intensity that can be differentiated from background and diffuse cytoplasmic staining (Phillips et al. 2015).
According to the de-facto consensus, membranous positivity of tumor cells was considered positive, whereas only cytoplasmic staining was disregarded (Scheel et al. 2016). The staining intensity was determined for each cell. The percentage of cells at each intensity was measured. Finally, the proportion and intensity of positive cells for each case were recorded. The positivity of PD-L1 status was determined based on 1\% and 5\% thresholds. For tumorinfiltrating lymphocytes, membranous and cytoplasmic staining cannot be reliably distinguished due to the small cell size, and PD-L1 staining of any intensity, either membranous or cytoplasmic, was considered positive (Scheel et al. 2016).

\section{BRAF and TERT promoter mutation test}

Genomic DNA was extracted using a Qiagen DNA FFPE Tissue Kit (Qiagen) according to the manufacturer's instruction. Semi-nested polymerase chain reaction (PCR) was carried out to identify TERT promoter mutations. First-round PCR was performed using primers TERT-F and TERT-236-R, as previously described (Sohn et al. 2016). The 235 bp-sized PCR amplicon was subjected to second-round PCR using primers TERT-F and TERT-163-R. PCR reactions were performed using a GeneAmp PCR system 9700 thermal cycler (Applied Biosystems). Cycle sequencing was performed using Big Dye Terminator Cycle Sequencing Ready Reaction kits (Applied Biosystems) on an ABI 3730xl Genetic Analyzer (Applied Biosystems).

For detection of the BRAF V600E mutation, the mutant enrichment with 3 '-modified oligonucleotides-PCR
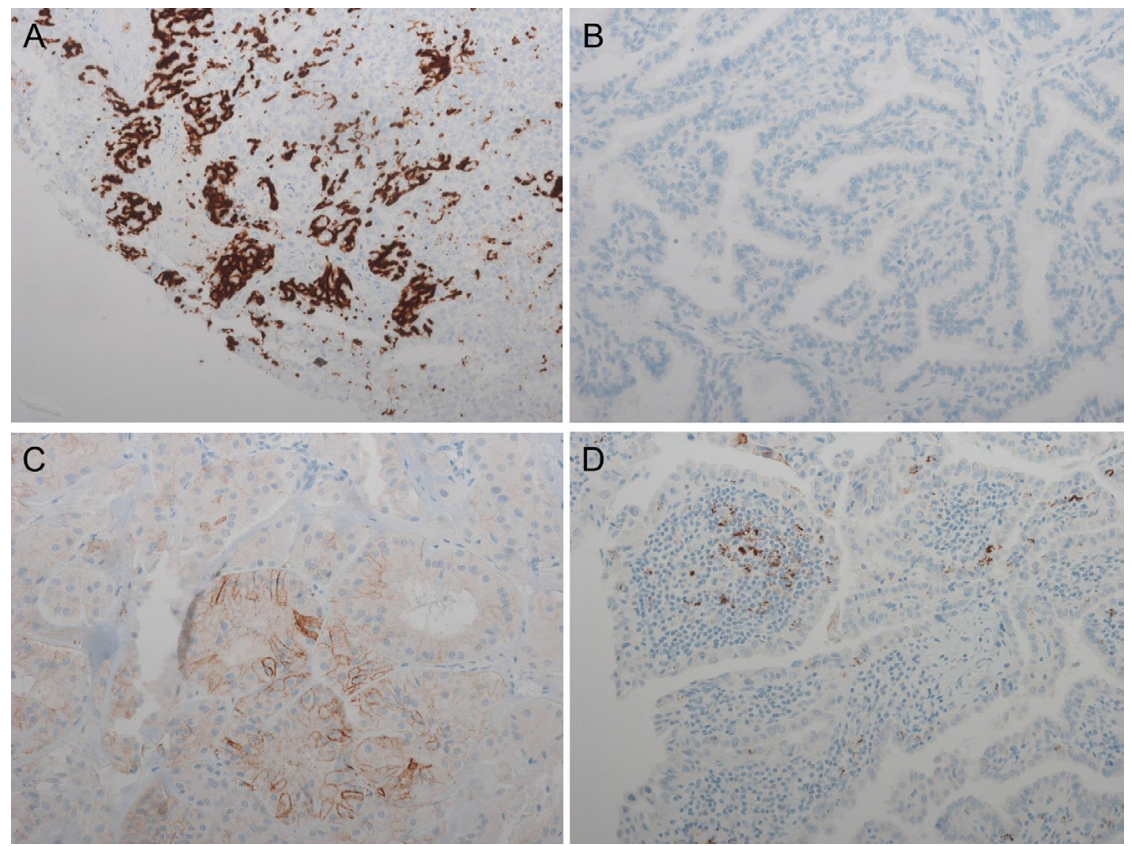

Figure 1

(A) Tonsillar squamous epithelium used as the positive control for PD-L1 staining. (B-D) PD-L1 staining in papillary thyroid cancers. (B) PD-L1negative staining. (C) PD-L1-positive staining in tumor cells with intensity $2+$ and $1+$ and (D) PD-L1-positive staining in intratumoral lymphocytes. A full colour version of this figure is available at http://dx.doi.org/10.1530/ ERC-16-0421. 
(MEMO-PCR) and direct sequencing was performed as described previously (Lee et al. 2012). The obtained sequences were analyzed using the Sequencher program (Gene Codes Corp., Ann Arbor, MI, USA) and were compared to a reference sequence (GenBank accession number NM_004333.4). BRAF mutation was tested in 322 available cases.

\section{Statistical analysis}

Statistical analysis was performed using SPSS, version 18.0. Contingency tables and $\chi^{2}$ tests were used to correlate PD-L1 immunohistochemistry results with tumor type, age, sex, pT stage, pN stage, Hashimoto disease, multiplicity, BRAF status, TERT promoter status, disease recurrence and cancer-specific death. Structural recurrence, as opposed to biochemical recurrence, was defined as recurrent or persistent disease determined pathologically or cytologically to be malignant tissue and/or highly suspicious metastatic lesions. Disease-free interval curves were drawn using Kaplan-Meier estimates and were compared using log-rank tests. A $P$ value $<0.05$ was considered to be significant.

\section{Results}

\section{Patient demographics and clinicopathologic variables}

Clinicopathologic characteristics of 407 patients according to PD-L1 status are presented in Table 1. The age of patients at the time of diagnosis ranged from 15.8 to 81.4 years (median 43.8 years). The median (IQR) follow-up was 13.7 (11.8-16.4) years. Among patients, 83\% were females and $17 \%$ were males. The proportions of papillary thyroid carcinoma, follicular thyroid carcinoma, poorly differentiated thyroid carcinoma and anaplastic thyroid carcinoma were $80.1 \%, 16.2 \%, 1.5 \%$ and $2.2 \%$, respectively. According to the AJCC classification, stages 1, 2, 3 and 4 consisted of $54.1 \%, 6.6 \%, 25.3 \%$ and $14.0 \%$, respectively. Hashimoto disease was present in 49 of 407 patients.

Among 380 patients without systemic metastasis at the initial presentation, 99 (26.1\%) developed structural recurrence. Of the 407 patients, 43 (10.6\%) deceased during follow-up and 38 (9.3\%) died of thyroid cancer. According to cancer types, 17 (5.2\%) of 326 patients with papillary thyroid carcinoma, ten (15.2\%) of 66 with follicular thyroid carcinoma, two (33.3\%) of six with poorly differentiated thyroid carcinoma and all nine patients with anaplastic thyroid carcinoma died of thyroid
Table 1 Clinicopathologic characteristic of 407 thyroid tumors according to PD-L1 status.

\begin{tabular}{|c|c|c|c|c|}
\hline \multirow[b]{2}{*}{ Variables } & \multicolumn{2}{|c|}{$\begin{array}{l}\text { PD-L1 immunohistochemisty } \\
\text { in tumor }\end{array}$} & \multirow[b]{2}{*}{ Total } & \multirow[b]{2}{*}{ P-valuc } \\
\hline & Negative & Positive & & \\
\hline \multicolumn{5}{|l|}{ Age } \\
\hline$<45$ & $212(55.8 \%)$ & $13(48.1 \%)$ & 225 & \multirow[t]{2}{*}{0.44} \\
\hline$\geq 45$ & $168(44.2 \%)$ & $14(51.9 \%)$ & 182 & \\
\hline \multicolumn{5}{|l|}{ Sex } \\
\hline Female & $318(83.7 \%)$ & $20(74.1 \%)$ & 338 & \multirow[t]{2}{*}{0.192} \\
\hline Male & $62(16.3 \%)$ & $7(25.9 \%)$ & 69 & \\
\hline \multicolumn{5}{|l|}{ Tumor size } \\
\hline$<2 \mathrm{~cm}$ & $42(11.1 \%)$ & $2(7.4 \%)$ & 44 & \multirow[t]{3}{*}{0.797} \\
\hline $2-4 \mathrm{~cm}$ & $282(74.2 \%)$ & $20(74.1 \%)$ & 302 & \\
\hline$>4 \mathrm{~cm}$ & $56(14.7 \%)$ & $5(18.5 \%)$ & 61 & \\
\hline \multicolumn{5}{|l|}{ Multiplicity } \\
\hline No & $280(73.7 \%)$ & $19(70.4 \%)$ & 299 & \multirow[t]{2}{*}{0.706} \\
\hline Yes & $100(26.3 \%)$ & $8(29.6 \%)$ & 108 & \\
\hline \multicolumn{5}{|l|}{ Extension } \\
\hline No & $102(26.8 \%)$ & $8(29.6 \%)$ & 110 & \multirow[t]{3}{*}{0.957} \\
\hline Yes & $231(60.8 \%)$ & $16(59.3 \%)$ & 247 & \\
\hline NA & $47(12.4 \%)$ & $3(11.1 \%)$ & 50 & \\
\hline \multicolumn{5}{|l|}{ Margin } \\
\hline Negative & $291(76.6 \%)$ & $22(81.5 \%)$ & 313 & \multirow[t]{3}{*}{0.648} \\
\hline Positive & $68(17.9 \%)$ & $3(11.1 \%)$ & 71 & \\
\hline NA & $21(5.5 \%)$ & $2(7.4 \%)$ & 23 & \\
\hline \multicolumn{5}{|l|}{ pT stage } \\
\hline $\mathrm{T} 1$ & $62(16.3 \%)$ & $2(7.4 \%)$ & 64 & \multirow[t]{6}{*}{0.062} \\
\hline $\mathrm{T} 2$ & $50(13.2 \%)$ & $6(22.2 \%)$ & 56 & \\
\hline T3 & $248(65.3 \%)$ & $16(59.3 \%)$ & 264 & \\
\hline $\mathrm{T} 4 \mathrm{a}$ & $19(5 \%)$ & $2(7.4 \%)$ & 21 & \\
\hline $\mathrm{T} 4 \mathrm{~b}$ & $1(0.3 \%)$ & $0(0 \%)$ & 1 & \\
\hline $\mathrm{Tx}$ & $0(0 \%)$ & $1(3.7 \%)$ & 1 & \\
\hline \multicolumn{5}{|l|}{ pN stage } \\
\hline No & $191(50.3 \%)$ & $14(51.9 \%)$ & 205 & 0.22 \\
\hline $\mathrm{N} 1 \mathrm{a}$ & $113(29.7 \%)$ & $8(29.6 \%)$ & 121 & \\
\hline N1b & $75(19.7 \%)$ & $4(14.8 \%)$ & 79 & \\
\hline $\mathrm{Nx}$ & $1(0.3 \%)$ & $1(3.7 \%)$ & 2 & \\
\hline Initial meta & & & & \\
\hline No & $354(93.2 \%)$ & $26(96.3 \%)$ & 380 & 0.45 \\
\hline Yes & $26(6.8 \%)$ & $1(3.7 \%)$ & 27 & \\
\hline TNM stage & & & & \\
\hline 1 & $207(54.5 \%)$ & $13(48.1 \%)$ & 220 & 0.11 \\
\hline 2 & $22(5.8 \%)$ & $5(18.5 \%)$ & 27 & \\
\hline 3 & $98(25.8 \%)$ & $5(18.5 \%)$ & 103 & \\
\hline 4 & $53(13.9 \%)$ & $4(14.8 \%)$ & 57 & \\
\hline Recurrence & & & & \\
\hline No & $264(74.6 \%)$ & $17(65.4 \%)$ & 281 & 0.303 \\
\hline Yes & $90(25.4 \%)$ & $9(34.6 \%)$ & 99 & \\
\hline Death & & & & \\
\hline Alive & $345(90.8 \%)$ & $24(88.9 \%)$ & 369 & 0.73 \\
\hline Dead & $35(9.2 \%)$ & $3(11.1 \%)$ & 38 & \\
\hline TERT prom & & & & \\
\hline Wild & $333(87.6 \%)$ & $25(92.6 \%)$ & 358 & 0.758 \\
\hline Mutated & $47(12.4 \%)$ & $2(7.4 \%)$ & 49 & \\
\hline$B R A F$ & & & & \\
\hline Wild & $112(37.5 \%)$ & $9(39.1 \%)$ & 121 & 0.873 \\
\hline Mutated & $187(62.5 \%)$ & $14(60.9 \%)$ & 201 & \\
\hline
\end{tabular}

(C) 2017 Society for Endocrinology Printed in Great Britain
Published by Bioscientifica Ltd. 
cancer. The BRAF V600E mutation was detected in 201 (62.4\%) of 322 tested cases. According to histologic type, it was detected in $75.3 \%$ (198 of 263) of papillary thyroid carcinoma, 25\% (1 of 4) of poorly differentiated thyroid carcinomas and $66.7 \%$ (2 of 3 ) of anaplastic thyroid carcinoma cases. BRAF mutation was detected in none of the 52 follicular thyroid carcinomas. TERT promoter mutations were detected in 49 (12.0\%) of 407 tested cases: $11.1 \%$ $(n=45)$ TERT C228T and 1.0\% $(n=4)$ C250T mutations. TERT promoter mutations were detected in $9.8 \%$ (32 of 326 ) of papillary thyroid carcinomas, $16.7 \%$ (11 of 66 ) of follicular thyroid carcinomas, 33.3\% (2 of 6) of poorly differentiated thyroid carcinomas and $44.4 \%$ (4 of 9) of anaplastic thyroid carcinoma cases.

\section{PD-L1 immunohistochemistry results}

Overall, tumoral PD-L1 was expressed in 27 (6.6\%) of 407 cases at a 1\% threshold. Regarding cancer types, PD-L1-positive staining was found in $6.1 \%$ of papillary thyroid carcinomas (20 of 326), $7.6 \%$ of follicular thyroid carcinomas (5 of 66 ), $22.2 \%$ of anaplastic thyroid carcinomas ( 2 of 9 ) and none of the poorly differentiated thyroid carcinomas. The distribution of PD-L1 positivity was significantly different according to cancer histology types $(P<0.001)$ (Table 2$)$. Most PD-L1-positive papillary thyroid carcinoma showed weak (1+) intensity with $<5 \%$ proportion of positivity (Fig. 1). When a 5\% threshold was applied, the positivity of PD-L1 in papillary thyroid carcinoma decreased to $0.9 \%$ (3 of 326). Follicular and anaplastic thyroid carcinoma showed no change in PD-L1 positivity when a 5\% threshold was applied. All PD-L1-positive follicular and anaplastic thyroid carcinomas showed strong intensity (2+ and 3+) (Fig. 2). The proportions of positive staining in two PD-L1positive anaplastic thyroid carcinomas were $80 \%$ and $90 \%$. The details of immunohistochemistry results and clinicopathologic information of PD-L1-positive tumors are summarized in Table 3.
Regarding tumor-infiltrating lymphocytes, PD-L1 was expressed in $93(28.5 \%)$ of 326 papillary thyroid carcinomas, 6 (9.1\%) of 66 follicular thyroid carcinomas, $1(11.1 \%)$ of 9 anaplastic thyroid carcinomas and none of poorly differentiated thyroid carcinomas. Although there was no association between accompanied Hashimoto disease and tumoral PD-L1 expression $(P=0.551)$, the frequency of PD-L1 expression in tumor-infiltrating lymphocytes was significantly higher in cases with Hashimoto disease (67.3\%) than cases without Hashimoto disease $(18.7 \%)(P<0.001)$ (Supplementary Table 1 , see section on supplementary data given at the end of this article). There was no significant association between PD-L1 expression in tumor cells and those in tumorinfiltrating lymphocytes $(P=0.866)$.

\section{Association of PD-L1 status with clinicopathologic variables}

The clinicopathologic characteristics of 407 patients according to tumoral PD-L1 status are presented in Table 1. There was no significant association between PD-L1 status and age, sex, tumor size, stage, initial metastasis, recurrence, death, BRAF and TERT promoter results.

As papillary thyroid carcinoma, follicular thyroid carcinoma, poorly differentiated thyroid and anaplastic thyroid carcinoma show distinctly different clinical behaviors, associations between clinicopathologic variables and PD-L1 results were separately analyzed. In thyroid carcinoma of papillary, follicular and anaplastic subtypes, there was no significant association between PD-L1 status clinicopathologic variables. Among 32 TERT promoter-mutated papillary thyroid carcinomas, two (6.3\%) cases revealed PD-L1 positivity, despite no statistical significance.

In addition, there was no association between clinicopathologic factors and PD-L1 expression in tumor-infiltrating lymphocytes for any type of thyroid carcinomas.

Table 2 Frequency of PD-L1 positivity.

\begin{tabular}{|c|c|c|c|c|}
\hline & \multicolumn{3}{|c|}{ PD-L1 immunohistochemistry in tumor } & \multirow[b]{3}{*}{ Total } \\
\hline & \multirow[b]{2}{*}{ Negative } & \multicolumn{2}{|c|}{ Positive } & \\
\hline & & $(1 \% \leq$ Proportion $<5 \%)$ & (Proportion $\geq 5 \%$ ) & \\
\hline Papillary carcinoma & $306(93.9 \%)$ & $17(5.2 \%)$ & $3(0.9 \%)$ & 326 \\
\hline Follicular carcinoma & $61(92.4 \%)$ & $0(0 \%)$ & $5(7.6 \%)$ & 66 \\
\hline Poorly differentiated carcinoma & $6(100 \%)$ & $0(0 \%)$ & $0(0 \%)$ & 6 \\
\hline Anaplastic carcinoma & $7(77.8 \%)$ & $0(0 \%)$ & $2(22.2 \%)$ & 9 \\
\hline Total & $380(93.4 \%)$ & $18(4.4 \%)$ & $9(2.2 \%)$ & 407 \\
\hline
\end{tabular}

$P<0.001$. 

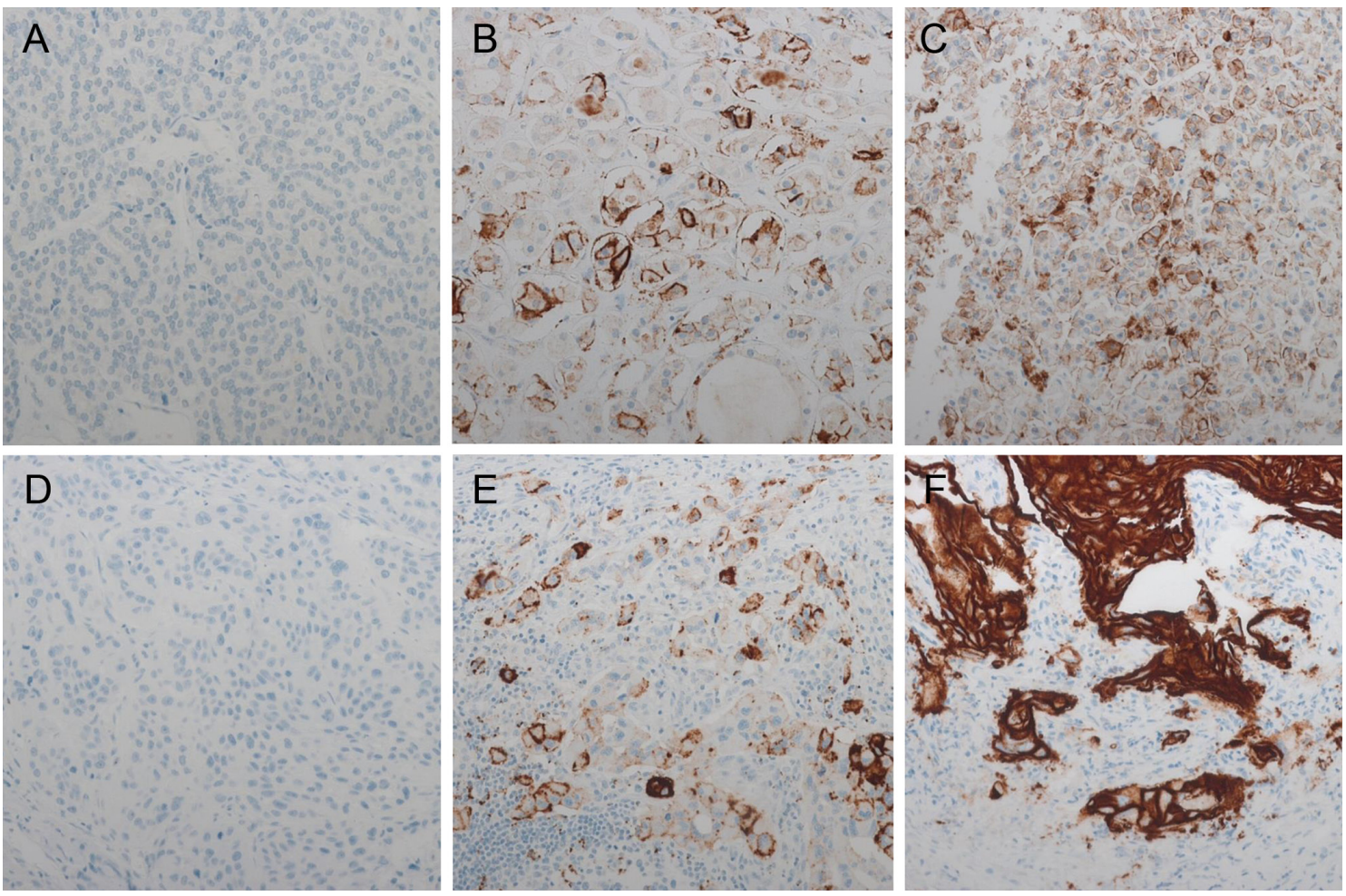

Figure 2

(A-C) PD-L1 staining in follicular thyroid carcinomas: (A) PD-L1-negative staining, (B) PD-L1-positive staining in tumor cells with intensity 3+ and 2+ and (C) PD-L1-positive staining in tumor cells with intensity 3+ and 2+. (D-F) PD-L1 staining in anaplastic thyroid carcinomas: (D) PD-L1 negative staining, (E) PD-L1-positive staining in tumor cells with intensity 3+ and 2+, and (F) PD-L1-positive staining in tumor cells with intensity 3+. A full colour version of this figure is available at http://dx.doi.org/10.1530/ERC-16-0421.

\section{Association of PD-L1 status with clinical outcome}

We did not find significant associations between tumoral PD-L1 expression and disease-free survival in papillary thyroid carcinoma $(P=0.123)$, follicular thyroid carcinoma $(P=0.398)$ and anaplastic thyroid carcinoma $(P=0.953)$. In addition, there was no statistically significant association between PD-L1 status and cancer-specific survival in papillary thyroid carcinoma $(P=0.955)$, follicular thyroid carcinoma $(P=0.345)$ and anaplastic thyroid carcinoma $(P=0.667)$.

PD-L1 negativity in tumor-infiltrating lymphocytes was associated with shorter cancer-specific survival in papillary thyroid carcinomas $(P=0.041)$. There was no association between PD-L1 expression in tumorinfiltrating lymphocytes and cancer-specific survival in follicular thyroid carcinomas and anaplastic carcinomas.

\section{Discussion}

We evaluated the PD-L1 expression in a large cohort of thyroid carcinoma patients with a median 13.7 years of follow-up period. We identified tumoral PD-L1 expression in $6.6 \%$ of our thyroid cancer cohort. Remarkably, PD-L1 expression was more frequent and staining intensity was stronger in anaplastic thyroid carcinomas and follicular thyroid carcinomas. All PD-L1-positive anaplastic thyroid carcinomas showed strong PD-L1 staining intensity and were positive in $\geq 80 \%$ of tumor cells. Anaplastic thyroid cancer is known to have a poor prognosis due to its aggressive and rapid metastasis with a median survival of less than six months (Lim et al. 2012). The first treatment option for anaplastic thyroid carcinoma is palliative surgery, followed by radiotherapy, chemotherapy or both (Pierie et al. 2002, Lim et al. 2012). However, many patients present with inoperable status and complete resection is possible for only up to one-third of patients at presentation (McIver et al. 2001, Lim et al. 2012). Therefore, identification of novel therapeutic targets is warranted for treatment of this aggressive thyroid cancer. Although infrequent, identification of PD-L1 expression in anaplastic cancer might have direct therapeutic relevance to patients. Two previous studies reported PD-L1 expression in anaplastic thyroid carcinomas, and the frequency of PD-L1 positivity was $75 \%$ and $23 \%$, respectively (Table 4) (Wu et al. 2015, Bastman et al. 2016).

Published by Bioscientifica Ltd. 
Table 3 Clinicopathologic information of PD-L1-positive thyroid cancers.

\begin{tabular}{|c|c|c|c|c|c|c|c|c|c|c|c|c|c|}
\hline $\begin{array}{l}\text { Case } \\
\text { no }\end{array}$ & $\begin{array}{l}\text { Histology } \\
\text { type }\end{array}$ & $\begin{array}{l}\text { PD-L1 in } \\
\text { tumor } \\
\text { (intensity, } \\
\text { proportion) }\end{array}$ & Age & Sex & $\begin{array}{l}\text { Size of } \\
\text { the } \\
\text { largest } \\
\text { tumor }\end{array}$ & Multiplicity & $\begin{array}{l}\text { PT } \\
\text { stage }\end{array}$ & $\begin{array}{l}\text { pN } \\
\text { stage }\end{array}$ & $\begin{array}{c}\text { TNM } \\
\text { stage }\end{array}$ & $\begin{array}{l}\text { TERT } \\
\text { promoter }\end{array}$ & BRAF & Recurrence & Death \\
\hline 1 & Papillary & $1+, 1 \%$ & 54 & Female & 2.5 & No & T3 & N1a & 3 & Wild & V600E & No recurrence & Alive \\
\hline 2 & Papillary & $1+, 1 \%$ & 42 & Male & 1.8 & No & T3 & N1a & 1 & Wild & V600E & No recurrence & Alive \\
\hline 3 & Papillary & $1+, 2 \%$ & 27 & Female & 5 & Yes & T3 & $\mathrm{N} 1 \mathrm{~b}$ & 1 & Wild & V600E & Recurrence & Alive \\
\hline 4 & Papillary & $2+, 1 \%$ & 36 & Female & 2.5 & No & $\mathrm{T} 2$ & N1a & 1 & Wild & V600E & Recurrence & Alive \\
\hline 5 & Papillary & $2+, 1 \%$ & 45 & Female & 2 & Yes & T3 & N1b & 1 & Wild & V600E & No recurrence & Alive \\
\hline 6 & Papillary & $1+, 2 \%$ & 42 & Female & 2.9 & Yes & T3 & N1a & 1 & Wild & V600E & No recurrence & Alive \\
\hline 7 & Papillary & $1+, 2 \%$ & 40 & Female & 3.6 & Yes & T3 & N1b & 1 & Wild & Wild & Recurrence & Alive \\
\hline 8 & Papillary & $1+, 2 \%$ & 34 & Female & 2.7 & No & T3 & No & 1 & Wild & V600E & No recurrence & Alive \\
\hline 9 & Papillary & $1+, 2 \%$ & 47 & Female & 2.3 & Yes & T3 & N1a & 3 & Wild & V600E & No recurrence & Alive \\
\hline 10 & Papillary & $1+, 2 \%$ & 39 & Female & 0.7 & Yes & T3 & N1a & 1 & Wild & NA & Recurrence & Alive \\
\hline 11 & Papillary & $1+, 2 \%$ & 61 & Male & 10.5 & No & $\mathrm{T} 4 \mathrm{a}$ & $\mathrm{N} 1 \mathrm{~b}$ & 4 & $\mathrm{C} 228 \mathrm{~T}$ & V600E & Recurrence & Dead \\
\hline 12 & Papillary & $1+, 2 \%$ & 53 & Female & 2.3 & No & T3 & No & 3 & Wild & NA & No recurrence & Alive \\
\hline 13 & Papillary & $1+, 3 \%$ & 45 & Male & 4 & No & T3 & NO & 1 & Wild & V600E & No recurrence & Alive \\
\hline 14 & Papillary & $2+, 2 \%$ & 30 & Female & 2.8 & No & T3 & No & 1 & Wild & Wild & Recurrence & Alive \\
\hline 15 & Papillary & $\begin{array}{r}2+, 2 \% \\
1+, 1 \%\end{array}$ & 50 & Male & 2 & No & $\mathrm{T} 1$ & No & 1 & Wild & V600E & No recurrence & Alive \\
\hline 16 & Papillary & $2+, 3 \%$ & 44 & Female & 2.5 & No & T3 & No & 1 & Wild & V600E & Recurrence & Alive \\
\hline 17 & Papillary & $2+, 3 \%$ & 54 & Male & 2.5 & No & T3 & N1a & 3 & Wild & V600E & No recurrence & Alive \\
\hline 18 & Papillary & $2+, 5 \%$ & 57 & Female & 3.5 & Yes & $\mathrm{T} 2$ & No & 2 & Wild & Wild & No recurrence & Alive \\
\hline 19 & Papillary & $\begin{array}{c}2+, 5 \% \\
1+, 30 \%\end{array}$ & 47 & Female & 2.5 & No & $\mathrm{T} 2$ & No & 2 & Wild & NA & No recurrence & Alive \\
\hline 20 & Papillary & $\begin{array}{c}3+, 5 \% \\
2+, 10 \% \\
1+, 40 \%\end{array}$ & 75 & Female & 5 & No & T3 & No & 3 & $\mathrm{C} 228 \mathrm{~T}$ & Wild & Recurrence & Alive \\
\hline 21 & Follicular & $\begin{array}{c}2+, 3 \% \\
1+, 15 \%\end{array}$ & 44 & Female & 3 & No & $\mathrm{T} 1$ & No & 1 & Wild & Wild & No recurrence & Alive \\
\hline 22 & Follicular & $\begin{array}{c}3+, 10 \% \\
2+, 5 \%\end{array}$ & 57 & Female & 5 & No & $\mathrm{T} 4 \mathrm{a}$ & No & 4 & Wild & Wild & No recurrence & Alive \\
\hline 23 & Follicular & $\begin{array}{r}2+, 20 \% \\
1+, 20 \%\end{array}$ & 40 & Female & 2.5 & No & $\mathrm{T} 2$ & No & 2 & Wild & Wild & No recurrence & Alive \\
\hline 24 & Follicular & $\begin{array}{r}3+, 10 \% \\
2+, 30 \%\end{array}$ & 46 & Male & 3 & No & $\mathrm{T} 2$ & No & 2 & Wild & Wild & No recurrence & Alive \\
\hline 25 & Follicular & $\begin{array}{r}3+, 30 \% \\
2+, 40 \%\end{array}$ & 55 & Female & 4 & No & $\mathrm{T} 2$ & No & 2 & Wild & Wild & No recurrence & Alive \\
\hline 26 & Anaplastic & $3+, 80 \%$ & 64 & Male & 5.1 & No & Tx & $\mathrm{Nx}$ & 4 & Wild & V600E & NA & Dead \\
\hline 27 & Anaplastic & $\begin{array}{l}3+, 60 \% \\
2+, 30 \%\end{array}$ & 72 & Female & 3 & Yes & T3 & N1a & 4 & Wild & NA & Recurrence & Dead \\
\hline
\end{tabular}

It is highly important to accurately select patients who may benefit from anti-PD-L1 therapy. Although some studies have shown minimal predictive value for PD-L1 expression, others have shown significantly increased response rates in expressers over nonexpressers (McLaughlin et al. 2016). Therefore, various studies by pharmaceutical companies have used their own companion diagnostic methods and various PD-L1 antibodies. However, PD-L1 assays for predicting response to monoclonal antibodies targeting PD-1 and PD-L1 are not standardized, with diverse commercially available assays yielding discordant results regarding PD-L1 expression and correlation to overall survival (McLaughlin et al. 2016). Several recent comparative studies of PD-L1 expression using different PD-L1 antibodies showed significant discordant results (McLaughlin et al. 2016, Scheel et al. 2016, Sun et al. 2016). Compared to other studies in thyroid cancer, PD-L1 positivity in papillary thyroid carcinoma patients was lower in our study (Table 4). In previous studies, PD-L1 positivity in papillary thyroid carcinoma was reported in up to $66.5 \%$ and $82.5 \%$ of cases (Cunha et al. 2013, Chowdhury et al. 2016). However, both used different antibodies (clone E1L3N and ab82059) from ours (SP142). As mentioned in a previous study, different antibodies were one contributing factor to different immunohistochemistry results. Three recent comparative studies including SP142 showed that SP142 stained less carcinoma cells compared to other immunohistochemistry 
Table 4 Prevalence of PD-L1 expression in thyroid cancers in reported studies.

$-\frac{\text { References }}{\text { Chowdhury et al. (2016) }}$
2 Angell et al. (2014)
3 Cunha et al. (2013)
4 Bastman et al. (2016)
5 Wu et al. (2015)

\begin{tabular}{c}
\hline $\begin{array}{c}\text { Frequency of PD-L1 } \\
\text { positivity }\end{array}$ \\
\hline $123 / 185(66.5 \%)$ \\
$74 / 185(40 \%)$ \\
$10 / 33(30.3 \%)$ \\
$209 / 254(82.3 \%)$ \\
$35 / 40(87.5 \%)$ \\
$7 / 12(58.3 \%)$ \\
$6 / 8(75 \%)$ \\
$3 / 13(23.1 \%)$ \\
\hline
\end{tabular}

\begin{tabular}{l} 
Localization of PD-L1 \\
protein (interpretation) \\
\hline Cytoplasmic \\
Membranous \\
Not mentioned \\
Cytoplasmic \\
Cytoplasmic \\
Membranous \\
Membranous \\
Not mentioned
\end{tabular}

PD-L1 detection antibody

E1L3N, cell signaling E1L3N, cell signaling \#4059 ab82059

ab82059

SP142

SP142 $5 \mathrm{H} 1$
( $2 \mathrm{~mm}$ ) for each case and tried to overcome the limitation of tissue microarray usage. To address intra-tumoral heterogeneity issue, we randomly chose 18 PD-L1negative cases and 15 positive cases in tissue microarray screening and performed PD-L1 in all cases with entire block. In 33 tested cases, there was no discordance between tissue microarray and whole slides. However, there is still a limitation of evaluating PD-L1 expression in tissue microarray. Another limitation is that we only tested one PD-L1 antibody. The SP142 antibody is a wellvalidated antibody used in several studies (Herbst et al. 2014, Powles et al. 2014), and has been recently approved as a companion diagnostic by the US Food and Drug Administration. Considering that different assays yield variable results, future studies are needed to compare PD-L1 positivity in thyroid cancer using variable assays with validation and propose a harmonized PD-L1 evaluation procedure.

Clinically, there was no significant association of PD-L1 expression with other clinicopathologic variables in this large-scale study. We did not demonstrate a significant prognostic value of tumoral PD-L1 expression in predicting poorer cancer-specific survival or disease-free survival, which was different from another study (Chowdhury et al. 2016). In addition, there was no association between the $B R A F$ mutation and PD-L1 expression in our cohort, which was inconsistent with a previous report (Angell et al. 2014). The $B R A F$ status was not available in subset of our cohort. Although the BRAF mutation rate $(75.2 \%)$ in papillary carcinoma was within the reported range from the population, there remains a possibility that untested cases for $B R A F$ mutation might alter the insignificant relationship between PD-L1 positivity and the mutational status. TERT promoter mutations are associated with an aggressive behavior of thyroid cancer including papillary thyroid carcinoma (Liu \& Xing 2016). Among 32 TERT promoter-mutated papillary thyroid carcinomas, two (6.3\%) cases revealed PD-L1 positivity. Of these two patients, one showed disease recurrence and the other 
patient died of thyroid cancer who might have benefited from anti-PD-1 immunotherapy. Lastly, the case number of anaplastic, poorly differentiated and follicular thyroid carcinomas was small in our study. Further large-scale study is expected to elucidate prevalence and prognostic significance of PD-L1 in aggressive thyroid cancers.

So far, few targeted therapies have been proven effective for anaplastic thyroid carcinomas. For patients with advanced differentiated (papillary and follicular) thyroid cancers, sorafenib, selumetinib, pazopanib and sunitinib have been investigated with promising results (Nixon et al. 2013). Anaplastic lymphoma kinase (ALK) rearrangement was reported in a subset of aggressive thyroid cancers (Kelly et al. 2014), and the availability of a small-molecule ALK inhibitor, crizotinib, has shown clinical promise in $A L K$-rearranged aggressive thyroid cancer (Godbert et al. 2015). As crizotinib was approved by the US Food and Drug Administration with a companion diagnostic test called the Vysis ALK Break Apart FISH Probe Kit, PD-L1 immunopositivity would be of clinical importance when considering anti-PD-L1 therapy in selected thyroid cancer patients. Currently, a trial with Atezolizumab for advanced solid tumors is recruiting patients with biomarker analysis (NCT02458638), which might address further questions.

In conclusion, we investigated PD-L1 expression using the SP142 antibody and found higher expression in a subset of advanced thyroid cancers such as anaplastic thyroid carcinoma and follicular thyroid carcinoma. Identification of PD-L1 expression may have direct therapeutic relevance to patients with refractory thyroid cancer.

\section{Supplementary data}

This is linked to the online version of the paper at http://dx.doi.org/10.1530/ ERC-16-0421

\section{Declaration of interest}

The authors declare that there is no conflict of interest that could be perceived as prejudicing the impartiality of the research reported.

\section{Funding}

This research was supported by Korean Foundation for Cancer Research grant (grant number CB-2011-03-02)

\section{References}

Angell TE, Lechner MG, Jang JK, Correa AJ, LoPresti JS \& Epstein AL 2014 BRAF V600E in papillary thyroid carcinoma is associated with increased programmed death ligand 1 expression and suppressive immune cell infiltration. Thyroid 24 1385-1393. (doi:10.1089/ thy.2014.0134)

Bastman JJ, Serracino HS, Zhu Y, Koenig MR, Mateescu V, Sams SB, Davies KD, Raeburn CD, McIntyre RC, Haugen BR Jr, et al. 2016 Tumor-infiltrating T Cells and the PD-1 checkpoint pathway in advanced differentiated and anaplastic thyroid cancer. Journal of Clinical Endocrinology \& Metabolism 101 2863-2873. (doi:10.1210/ jc.2015-4227)

Chowdhury S, Veyhl J, Jessa F, Polyakova O, Alenzi A, MacMillan C, Ralhan R \& Walfish PG 2016 Programmed death-ligand 1 overexpression is a prognostic marker for aggressive papillary thyroid cancer and its variants. Oncotarget 7 32318-32328. (doi:10.18632/ oncotarget.8698)

Cunha LL, Marcello MA, Morari EC, Nonogaki S, Conte FF, Gerhard R, Soares FA, Vassallo J \& Ward LS 2013 Differentiated thyroid carcinomas may elude the immune system by $\mathrm{B} 7 \mathrm{H} 1$ upregulation. Endocrine-Related Cancer 20 103-110. (doi:10.1530/ERC-12-0313)

Dong H, Strome SE, Salomao DR, Tamura H, Hirano F, Flies DB, Roche PC, Lu J, Zhu G, Tamada K, et al. 2002 Tumor-associated B7-H1 promotes T-cell apoptosis: a potential mechanism of immune evasion. Nature Medicine 8 793-800. (doi:10.1038/nm730)

Garon EB, Rizvi NA, Hui R, Leighl N, Balmanoukian AS, Eder JP, Patnaik A, Aggarwal C, Gubens M, Horn L, et al. 2015 Pembrolizumab for the treatment of non-small-cell lung cancer. New England Journal of Medicine 372 2018-2028. (doi:10.1056/NEJMoa1501824)

Godbert Y, Henriques de Figueiredo B, Bonichon F, Chibon F, Hostein I, Perot G, Dupin C, Daubech A, Belleannee G, Gros A, et al. 2015 Remarkable response to crizotinib in woman with anaplastic lymphoma kinase-rearranged anaplastic thyroid carcinoma. Journal of Clinical Oncology 33 e84-e87. (doi:10.1200/JCO.2013.49.6596)

Herbst RS, Soria JC, Kowanetz M, Fine GD, Hamid O, Gordon MS, Sosman JA, McDermott DF, Powderly JD, Gettinger SN, et al. 2014 Predictive correlates of response to the anti-PD-L1 antibody MPDL3280A in cancer patients. Nature 515 563-567. (doi:10.1038/ nature14011

Kelly LM, Barila G, Liu P, Evdokimova VN, Trivedi S, Panebianco F, Gandhi M, Carty SE, Hodak SP, Luo J, et al. 2014 Identification of the transforming STRN-ALK fusion as a potential therapeutic target in the aggressive forms of thyroid cancer. PNAS $1114233-4238$. (doi:10.1073/pnas.1321937111)

Lee ST, Kim SW, Ki CS, Jang JH, Shin JH, Oh YL, Kim JW \& Chung JH 2012 Clinical implication of highly sensitive detection of the BRAF V600E mutation in fine-needle aspirations of thyroid nodules: a comparative analysis of three molecular assays in 4585 consecutive cases in a BRAF V600E mutation-prevalent area. Journal of Clinical Endocrinology \& Metabolism 97 2299-2306. (doi:10.1210/jc.2011-3135)

Lim SM, Shin SJ, Chung WY, Park CS, Nam KH, Kang SW, Keum KC, Kim JH, Cho JY, Hong YK, et al. 2012 Treatment outcome of patients with anaplastic thyroid cancer: a single center experience. Yonsei Medical Journal 53 352-357. (doi:10.3349/ymj.2012.53.2.352)

Liu R \& Xing M 2016 TERT promoter mutations in thyroid cancer. Endocrine-Related Cancer 23 R143-R155. (doi:10.1530/ERC-15-0533)

McIver B, Hay ID, Giuffrida DF, Dvorak CE, Grant CS, Thompson GB, van Heerden JA \& Goellner JR 2001 Anaplastic thyroid carcinoma: a 50-year experience at a single institution. Surgery 130 1028-1034. (doi:10.1067/msy.2001.118266)

McLaughlin J, Han G, Schalper KA, Carvajal-Hausdorf D, Pelekanou V, Rehman J, Velcheti V, Herbst R, LoRusso P \& Rimm DL 2016 Quantitative assessment of the heterogeneity of PD-L1 expression in non-small-cell lung cancer. JAMA Oncology 2 46-54. (doi:10.1001/ jamaoncol.2015.3638)

Nixon IJ, Shaha AR \& Tuttle MR 2013 Targeted therapy in thyroid cancer. Current Opinion in Otolaryngology \& Head and Neck Surgery 21 130-134. (doi:10.1097/MOO.0b013e32835aa2c2)

Ohaegbulam KC, Assal A, Lazar-Molnar E, Yao Y \& Zang X 2015 Human cancer immunotherapy with antibodies to the PD-1 and http://erc.endocrinology-journals.org

DOI: $10.1530 /$ ERC-16-0421
(C) 2017 Society for Endocrinology Printed in Great Britain 
PD-L1 pathway. Trends in Molecular Medicine 21 24-33. (doi:10.1016/j.molmed.2014.10.009)

Page DB, Postow MA, Callahan MK, Allison JP \& Wolchok JD 2014 Immune modulation in cancer with antibodies. Annual Review of Medicine 65 185-202. (doi:10.1146/annurev-med-092012-112807)

Patel SP \& Kurzrock R 2015 PD-L1 expression as a predictive biomarker in cancer immunotherapy. Molecular Cancer Therapeutics 14 847-856. (doi:10.1158/1535-7163.MCT-14-0983)

Phillips T, Simmons P, Inzunza HD, Cogswell J, Novotny J Jr, Taylor C \& Zhang X 2015 Development of an automated PD-L1 immunohistochemistry (IHC) assay for non-small cell lung cancer. Applied Immunohistochemistry \& Molecular Morphology 23 541-549. (doi:10.1097/PAI.0000000000000256)

Pierie JP, Muzikansky A, Gaz RD, Faquin WC \& Ott MJ 2002 The effect of surgery and radiotherapy on outcome of anaplastic thyroid carcinoma. Annals of Surgical Oncology 9 57-64. (doi:10.1245/aso.2002.9.1.57)

Powles T, Eder JP, Fine GD, Braiteh FS, Loriot Y, Cruz C, Bellmunt J, Burris HA, Petrylak DP, Teng SL, et al. 2014 MPDL3280A (anti-PD-L1) treatment leads to clinical activity in metastatic bladder cancer. Nature 515 558-562. (doi:10.1038/nature13904)

Rosenberg JE, Hoffman-Censits J, Powles T, van der Heijden MS, Balar AV, Necchi A, Dawson N, O'Donnell PH, Balmanoukian A, Loriot Y, et al. 2016 Atezolizumab in patients with locally advanced and metastatic urothelial carcinoma who have progressed following treatment with platinum-based chemotherapy: a single-arm, multicentre, phase 2 trial. Lancet 387 1909-1920. (doi:10.1016/ S0140-6736(16)00561-4)

Scheel AH, Dietel M, Heukamp LC, Johrens K, Kirchner T, Reu S, Ruschoff J, Schildhaus HU, Schirmacher P, Tiemann M, et al. 2016 Harmonized PD-L1 immunohistochemistry for pulmonary squamous-cell and adenocarcinomas. Modern Pathology 29 1165-1172. (doi:10.1038/modpathol.2016.117)

Sohn SY, Park WY, Shin HT, Bae JS, Ki CS, Oh YL, Kim SW \& Chung JH 2016 Highly concordant key genetic alterations in primary tumors and matched distant metastases in differentiated thyroid cancer. Thyroid 26 672-682. (doi:10.1089/thy.2015.0527)

Sul J, Blumenthal GM, Jiang X, He K, Keegan P \& Pazdur R 2016 FDA approval summary: pembrolizumab for the treatment of patients with metastatic non-small cell lung cancer whose tumors express programmed death-ligand 1. Oncologist 21 643-650. (doi:10.1634/theoncologist.2015-0498)

Sun WY, Lee YK \& Koo JS 2016 Expression of PD-L1 in triple-negative breast cancer based on different immunohistochemical antibodies. Journal of Translational Medicine 14 173. (doi:10.1186/s12967-0160925-6)

Taube JM, Anders RA, Young GD, Xu H, Sharma R, McMiller TL, Chen S, Klein AP, Pardoll DM, Topalian SL, et al. 2012 Colocalization of inflammatory response with B7-h1 expression in human melanocytic lesions supports an adaptive resistance mechanism of immune escape. Science Translational Medicine 4 127ra137. (doi:10.1126/scitranslmed.3003689)

Topalian SL, Taube JM, Anders RA \& Pardoll DM 2016 Mechanism-driven biomarkers to guide immune checkpoint blockade in cancer therapy. Nature Reviews Cancer 16 275-287. (doi:10.1038/nrc.2016.36)

Wu H, Sun Y, Ye H, Yang S, Lee SL \& de las Morenas A 2015 Anaplastic thyroid cancer: outcome and the mutation/expression profiles of potential targets. Pathology \& Oncology Research 21 695-701. (doi:10.1007/s12253-014-9876-5)

Xu B \& Ghossein R 2016 Genomic landscape of poorly differentiated and anaplastic thyroid carcinoma. Endocrine Pathology 27 205-212. (doi:10.1007/s12022-016-9445-4)

Received in final form 30 November 2016

Accepted 13 December 2016
() 2017 Society for Endocrinology Printed in Great Britain
Published by Bioscientifica Ltd 